\title{
The Neurologic Outcome Of Posterior Fixation Of Thoraco- Lumbar Spine Fractures In A Rural Tertiary Care Centre Without Help Of Image Intensifier
}

\author{
S Mondal ${ }^{1}$, A Chowdhury ${ }^{2}$ \\ Department of Orthopaedics, B.S.Medical College, West Bengal, Indial \\ Department of Community Medicine, B.S.Medical College, West Bengal, India 2
}

\begin{abstract}
Thirtyfive patient with unstable fractures of the lower thoracic and lumbar spine managed uniformly with Hartshill fixation and sublaminar wiring were analyzed. On admission, 18 patients had complete neurologic deficit and 17 had incomplete lesions. The neurologic recovery and functional activities were assessed after an average follow up for 20.4 months. Improvement of neural function was seen in 71 \% patients. Positive correlation was found between the level of injury and Frankel grades. The cord lesions tended to demonstrate more severe neurologic deficit than cauda equina lesions. A component of dislocation to the injury also resulted in a more severe neural deficit. The complications were minor. Stable fixation of thoracolumbar spine fractures was helpful in decreasing hospital stay and recumbency period, thereby facilitating early rehabilitation of the spine injured patients.
\end{abstract}

Keywords: Thoracolumbar spine -fracture-neurologic outcome- posterior fixation.

\section{Introduction:}

The treatment of thoracolumbar spine fractures remains controversial as there are proponents of both non-surgical and operative procedures. The goals of surgical management include anatomical alignment and maintenance of reduction of spine and effective decompression of the spinal canal, providing stability, early and pain free mobilization, minimizing complications, shorten hospital stay and encourage effective rehabilitation. There are wide range of posterior instrumentation techniques available for fixation like Harrington distraction rods, wired distraction rods, sub-laminar wiring of L-rods, and more recently pedicle screw fixation and AO spinal internal fixator. Controversy also remains whether decompression should or should not be performed ${ }^{2,3}$ and whether a posterior or anterior approach is indicated if decompression is deemed necessary, ${ }^{[7],[8],}$. The purpose of this study was to evaluate the results of posterior fixation of thoracolumbar spine fractures using Hartshill rectangle and sub-laminar wiring in view of limited available resources and to evaluate neurologic recovery following surgery.

\section{Materials And Methods}

During the period July2010 to January 2013,35 patients of unstable fractures of lower thoracic, thoraco-lumbar or lumbar spine with neurologic deficit were treated by Hartshill rectangle fixation with sublaminar wiring and autogenous bone grafting from iliac crest. Spinal instability was assessed according to Denis three column concept ${ }^{10}$ and criteria of McAfee et al. $\stackrel{2}{2}$ Stable fractures and unstable fractures without neurologic deficit were not subjected to surgery. Thirty five patients were available with sufficient data for follow-up analysis in our series at an average of 20.4 months (range 12-28 months).

The patients reported to our hospital at a mean of 55 hours (range 4-336 hours) after the injury. The mean age of the patients was 33 years (range 10- 62 years). There were 18 male and 17 female patients. The cause of injury was fall from height in 32 (tree -25 , building - 3, hill slope --2, electric pole --1, stairs --1), motor vehicle accident in one and heavy blow by a falling object in 2 patients. The level of injury was thoracic spine (T5-T11) in 7, thoracolumbar junction (T12-L1) in 24 and lumbar spine $\left(\mathrm{L}_{2}-\mathrm{L}_{5}\right)$ in 5 patients. The fractures were classified according to Denis classification ${ }^{10}$. There were 28 burst fractures and 7 fracture dislocations. Associated injuries (fracture ribs, fracture lower end of radius and elbow dislocation) were present in 5 patients.

The magnitude of the neural deficit was quantified both at the time of initial injury and at follow up by Frankel's grading ${ }^{11}$. In addition a modified Motor Trauma Index Score (MIS) as recommended by the American Spine Injury Association was assigned to each patient, both at injury and at follow up ${ }^{11}$. This score quantitates muscle strength from 0 to 5 for each of five muscle groups in each extremity. A complete paraplegia would therefore have a score of 50 points and patient with normal motor exam a score of 100 points. The lower extremity muscle groups tested included the hip flexors, quadriceps, tibialis anterior, external hallucis longus and gestrocnemius - soleus. 
The patients were operated at a mean interval of 10 days after hospitalization (rang 3-25 days). No direct decompression was performed in any of our cases. Sitting with back support and an ASH brace was permitted 24 hours after surgery. Wheel chair mobilization was started 48-72 hours after surgery. The patients were discharged at an average of 14 days after surgery (range 6-28 days).

After discharge, the patients were followed by means of regular visits to the spine injury clinic to assess the functional (neurologic) recovery and encourage early rehabilitation.

\section{Figures}

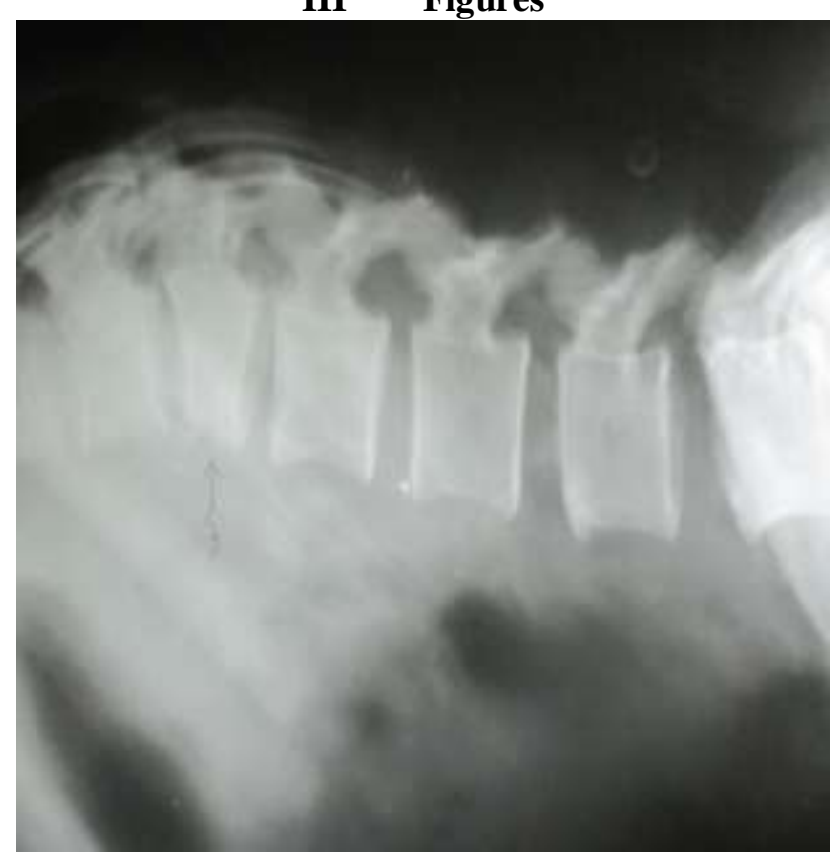

Fig:1 Pre-op. skiagram of LS spine showing anterior wedge compression fracture of L1 vertebrae.

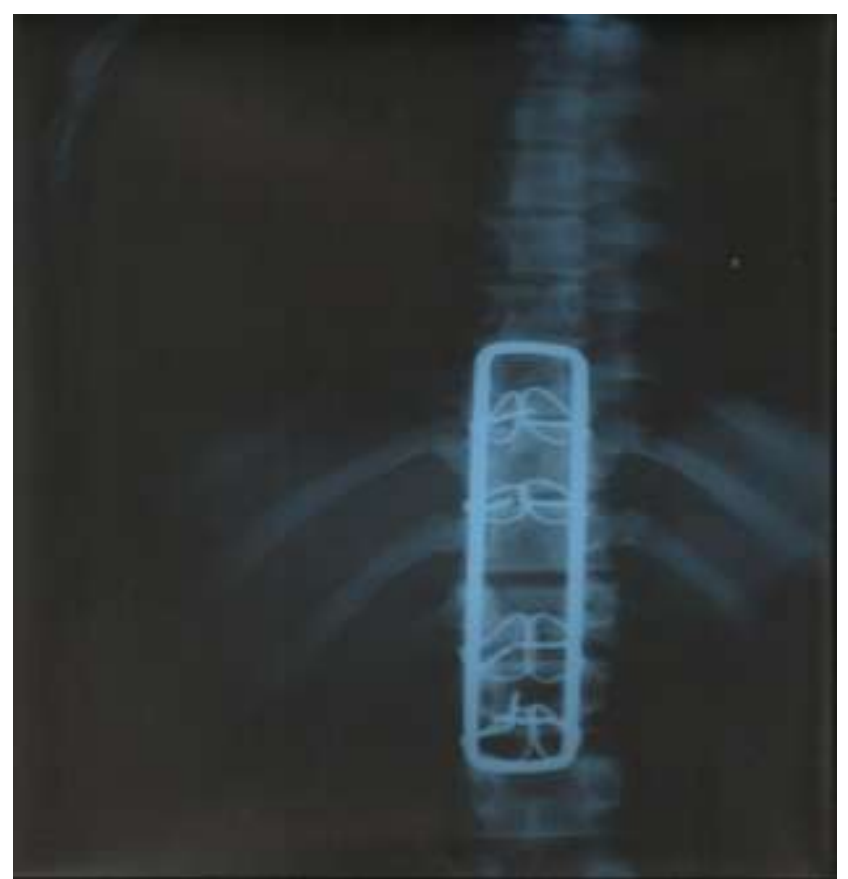

Fig: 2 Post operative skiagram LS spine AP view showing fixation with hartshill rod and autogenous cancellous bone grafting 


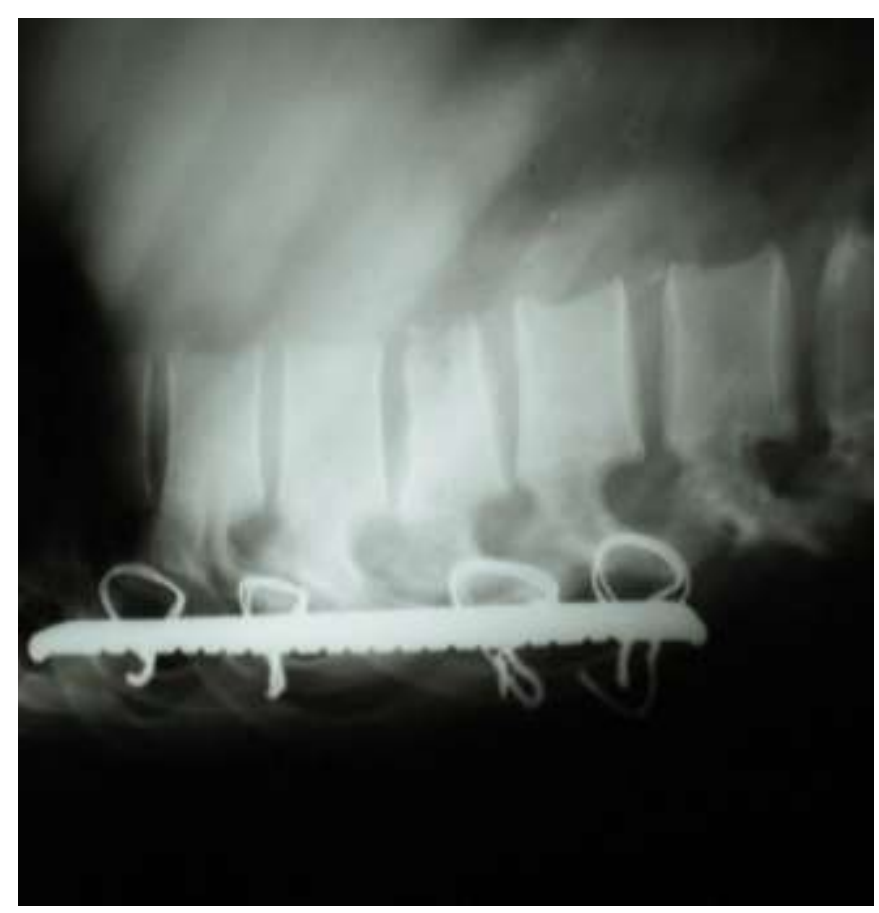

Fig:3 Post operative skiagram LS spine lateral view showing fixation with hartshill rod and autogenous cancellous bone grafting

\section{Results}

There were 18 patients with Frankel grade A, of whom nine improved. Five of the 6 patients in the grade B category improved to Frankel grade C, D or E and the remaining one patient improved within its grade. All ten patients with Frankel grade $\mathrm{C}$ and one patient with Frankel grade D improved to grade E. There were no patients without any neurologic deficit in the present series. No patient worsened neurologically till the time of last follow up.

The average improvement for the entire group was 1.3 grades ( 0.8 in grade A, 1.8 in grade $\mathrm{B}, 2$ in grade $\mathrm{C}$ and one in grade $\mathrm{D}$ ). If the 18 Frankel grade $\mathrm{A}$ patients were excluded, the average improvement was 1.9 grades. There was improvement of at least one Frankel grade in $71 \%$ of the patients in the entire series. If the eighteen Frankel grade A patients were excluded, the improvement was $94 \%$. The initial MIS was closely related to the initial Frankel grade. The average improvement in MIS for the entire series was 17 points with the eighteen grade A patient included and 28 points without them Burst fractures resulted in Frankel grades B,C and $\mathrm{D}$ primarily, where as the fracture dislocation injuries produced Frankel grade A in all cases. Of the 11 burst fractures producing Frankel grade A neurologic injury, eight improved by at least one Frankel grade. Only one of seven Frankel grade A patients of fracture dislocation improved by at least one Frankel grade Of the six patients with cord injuries, $5(83 \%)$ were Frankel grade A whereas of the 5 cauda equina lesions, $80 \%$ were Frankel grade B,C and D.

All patients with final Frankel grades A, B and C remained wheel chair bound Two patients with final Frankel grades D were ambulatory with support and 14 in grade E could walk freely at the last follow up.

\section{Complications}

There were 18 complications associated with Hartshill fixation in 10 patients. Superficial wound infection in two and urinary tract infection in ten patients was adequately controlled with appropriate antibiotics. In two of the 3 patients, bed sores healed after adequate nursing care and the remaining one required rotation flaps. Insignificantwire breakage at one level was observed in three patients which did not require repeat surgery.

\section{Discussion}

The most common mode of injury in our series was fall from height $(91 \%)$. This is contrary to the literature reports where motor vehicle accidents account for majority of spinal injuries (40-60\%) ${ }^{1,2,8,9}$ This may be because most of the people climb up the trees to collect leaves for their livestock. 
After sustaining the injury, there was a delay of average 55 hours (range 4-336 hours) in reporting to our hospital. This is due to inaccessible roads and poor means of transport and delay in referral from peripheral health centres.

Controversy remains as to whether treatment of unstable spinal injuries should be operative or nonoperative. Various literature reports have documented improved realignment and stabilization of fractures, and decreased hospital stay and recumbency after surgical fixation. ${ }^{6}$ In the present series, all patients were able to sit with support 24 hours after surgery. Wheel chair mobilization was started 48-72 hours after surgery, which simplified the nursing care and facilitated early rehabilitation in our patients.

Segmental fixation with Hartshill rectangle and sub-laminar wiring has less ability to support axial loads and restore vertebral body height and contours in comparison to Harrington distraction system, pedicle screw system $\underline{6}$ and AO spinal internal fixator. The reason for using this fixation device in our cases was no requirement of sophisticated costly instrumentation or IITV and less financial burden to our patients of poor socioeconomic status.

Krompinger et. al postulated that in the absence of neural deficit, fractures with more than 50 percent canal compromise and a kyphosis more than 30 degrees require surgical intervention to prevent late instability . Thoracolumbar spine fractures without neural deficit were not stabilized by fixation as the kyphosis was less than 30 degrees in all these cases and therefore, not included in our series.

Till date there is no ideal method of grading neurologic recovery. The Frankel system can be quite misleading. For example, a change from Frankel A to C (two grades) may represent only a gain of a small amount of movement in one muscle group, whereas a change from Frankel D to E (one grade) may be much more important. In addition, a patient may begin as a Frankel D and not gain an entire grade but have more return than a patient who went from $\mathrm{A}$ to $\mathrm{C} .{ }^{16}$

Changes in the MIS are easy to use and may represent a more accurate way to quantitate neurologic change. However, problems still exist, since a change from 50-80 points may be less important than a change from 80-100 points. ${ }^{11}$ The above problems make comparison with studies in the literature difficult.

The role of surgery in neural recovery is highly debated. Patient recovery by at least one Frankel grade of incomplete lesions treated non-operatively is about 65 to $70 \%,{ }^{12,13}$ although Davies et al reported an improvement rate of $95 \% .{ }^{14}$ In patients reviewed from the literature who underwent surgery, the recovery rates are somewhat higher $(75-88 \%), 1,871 \%$ of our patients improved at least one Frankel grade in the entire series. If Frankel grade A patients were excluded, 94\% patients with incomplete lesions improved at least one Frankel grade.

A few authors have reported better neurologic recovery with decompression. ${ }^{1,8}$ Anterior surgery is considered to be the most effective way of decompressing the spinal canal. ${ }^{8}$ But most authors agree that there is no relationship between spinal canal narrowing, neurologic deficit and improvement in neurologic status after surgery and hence, there is no need of removing retropulsed bone fragments from the spinal canal. ${ }^{7,11,15,16}$ Spontaneous canal remodeling has been reported in both non-operated 2 and operated cases. ${ }^{6}$ There are few reports to suggest that neurologic injury occurs at the time of trauma rather than being a result of pressure from fragments in the canal afterwards and question the need to operate simply to remove these fragments. ${ }^{15,16}$ Decompression was not done in any case in the present study.

A close relationship has been shown between the type of injury and Frankel grades, that is, fracture dislocation is associated with more severe neurologic grade than burst fracture. 3 In the present series, $54 \%$ of patients remained wheel chair bound till the last follow up and most of them were from initial Frankel grade A group (89\%). Useful functional activity (ambulating with or without support) was achieved in $46 \%$ patients and most of these patients $(94 \%)$ had incomplete neural deficit at the time of injury. Thus functional activities could be predicted to some extent from the initial Frankel grades. Functional activities were also directly related to the final Frankel grades of the patients

\section{References}

[1] Akalm S, Kis M, Benli IT, Citak M, Mumcu EF, Tuzuner M. Results of the AO spinal internal fixator in the surgical treatment of thoracolumbar burst fractues. Eur Spine J 1994; 3 : 102-106.

[2] McAfee PC, Yuan HA, Lasda NA. The unstable burst fracture. Spine $1982 ; 7$ : 365-373.

[3] Tasdemiroglu E, Tibbs PA. Long-term follow-up results of thoracolumbar fractures after posterior instrumentation. Spine 1995 ; 20 : 1704-1708

[4] Sullivan JA. Sublaminar wiring of Harrington distraction rods for unstable thoracolumbar spine fractures. Clin Orthop 1984; 189 : $178-185$.

[5] Ferguson RL, Allen BL. A mechanistic classification of thoracolumbar spine fracture. Clin Orthop 1984; 189 : $77-88$.

[6] Sjostrom L, Jacobsson O, Karlstrom G, Pech P, Rauschning W. Spinal canal remodelling after stabilization of thoracolumbar burst fractures. Eur Spine J 1994; $3: 312-317$.

[7] Kim NH, Lee HM, Chun IM. Neurologic injury and recovery in patients with burst fracture of the thoracolumbar spine. Spine 1999 $; 24: 290-294$.

[8] Bradford DS, McBride GG. Surgical management of thoracolumbar spine fractures with incomplete neurologic deficits. Clin Orthop North Am 1987 ; 218 : 201-216. 
[9] Dall BE, Stauffer ES. Neurologic injury and recovery patterns in burst fractures at the T12 or L1 motion segment. Clin Orthop North Am 1988 ; 233 : 171-176.

[10] Denis F. The three column spine and its significance in the classification of acute thoracolumbar spinal injuries. Spine 1983 ; 8 : 817 -831 .

[11] Herndon WA, Galloway D. Neurologic return versus cross sectional canal area in incomplete thoracolumbar spinal cord injuries. $J$ Trauma $1988 ; 28: 680-683$.

[12] Frankel HL, Hancock DD, Hyslop G, Melzak J, Michaelis LS, Ungar GH, Vernon JDS, Walsh JJ. The value of postural reduction in the initial management of closed injuries of the spine with paraplegia and tetraplegia. Paraplegia 1969; $7: 179-192$.

[13] Jacobs RR, Asher MA, Snider RK. Thoracolumbar spi nal injuries : A comparative study of recumbent and operative treatment in 100 patients. Spine $1980 ; 5: 463-477$.

[14] Davies WE, Morris JH, Hill V. A analysis of conservative (non surgical) management of thoracolumbar fractures and fracture dislocations with neurological damage. J Bone Joint Surg [Am] 1980 ; 62-A : 1324-1328.

[15] Limb D, Shaw DL, Dickson RA. Neurological injury in thoracolumbar burst fractures. J Bone Joint Surg [Br] 1995; 77-B : 774777.

[16] Shuman WP, Rogers JV, Sickler ME, Hanson JA, Crutcher JP, King HA, Mack LA. Thoracolumbar burst fractures : CT dimensions of the spinal canal relative to post-surgical improvement. AJR 1985; 145 : 337 - 341. 